\title{
Theory of Alamin
}

\section{(A Formation of Universal Communication Formula)}

\author{
Muhammad Aminullah \\ Lecturer in Da'wah and Communication Faculty, IAI Al-Aziziyah Samalanga, Kab Bireuen, Aceh, Indonesia \\ aminullahtengku@gmail.com
}

\begin{abstract}
Studies of this study need to be done to understand the basic nature of communication, so that the formation of a universal communication formula. The communication formula constructed in the theory of nature, explains that communication can be done in the form of a universal relationship ,not limited to the relationship between fellow human beings. It turns out that communication can be done in the form of relationships with all the elements that exist in the Universe of the universe is based on only one aspect of the relationship can be done on the need. Relationships that are built on necessities are an absolute right for humans to survive in their lives. The methodological approach in this research is the scientific approach that is built based on the discipline of ALAMTOLOGI. The communication formulas that are awakened in natural theory based on the discipline of ALAMTOLOGI communication and applied on all aspects of human relationships with others scientifically, systematically and universally in everyday life in a harmony way. The NAMORY THEORY formula is $X+Z(Y) \Leftrightarrow g H p$ and $X-Z(0) \Leftrightarrow g$ Cp. Based on this concept the implementation of communication of this formula in the implementation of communication can ensure its attainment to the value of harmony or lameness value. Good communication is harmony communication.
\end{abstract}

Keywords: Alamin, formula, communication, universal.

\section{INTRODUCTION}

The communication that developed during this explains about human relationships. Therefore, communication is conveying information or ideas rather than messengers to the recipient of the 
message, so that the recipient of the message will understand as understood by the messenger. As applicable, for example in relationship A with $\mathrm{B}$, then the information contained in A conveys to $\mathrm{B}$, then $\mathrm{B}$ will understand the message conveyed by $\mathrm{A}$ and vice versa that the information contained in $\mathrm{B}$ passes to A, then A will understand the message delivered by B.Thus, the formation of one's relationship with another due to the interaction that formed the result of a communication in the relationship. The most basic element in communication is the language either verbally or non verbally. So with the communication, can form a relationship with one another, a group with another group, one nation with other nations and also one country with other countries so as to achieve the relationship of all humans on earth. This communication is formed because of the need for each person, so require to others to complement each process required by each person. Thus, communication becomes a system that is formed rather than a process of interaction performed by someone with another to make a complementary relationship to every process that applies. Based on this concept emerged various forms of study existing in communication such as language communication, cultural communication, communication ethics, public communications even to emerge recent studies such as political communication, communication propaganda and various other studies about communication. So the ultimate goal is with the communication, can understand and share information, ideas and skills to others in the form of symbols, sounds, images rajah, numbers and graphs. Based on this concept can be understood that the communication into a system that is formed rather than the process of interaction in a relationship with someone else.

The process of interaction is the most important element for humans, because humans are social beings who cannot live without any relationship with others. Here the actual mention of human beings as social beings, not only in the form of relationships among human beings alone, but the human guard cannot be separated from relationships with other than humans, such as the need to eat, drink, rest, relieve and others. So for the perfection of this process, humans need another relationship that needs to be understood about how interactions can be made between humans and non-humans. In the study of communication is actually the process of interaction is not limited to human relationships alone, but need to open space to understand the process of interaction with other than humans. This is because humans also cannot be separated from relationships with other than humans. So here comes the process 
of interaction in communication systems that shape the way human relations with other than humans. This means that human relationships with other than humans not only limited to the subject relationship with the object, but there is another side in the form of subject relations with the subject. Human communication with other than humans actually becomes a new space that must be studied in the science of communication.

In order for communication to form a balanced value in the implementation, which is to establish the system in human relationships and also establish a system of relationships with other than humans. Therefore, then here comes the one study called THEORY ALAMIN . This theory explains that communication is not limited among human beings, but communication also exists with other than humans, but the way its implementation is different. This is due to follow his needs. This theory is not to obstruct or reject the available theories of communication, but THEORY ALAMIN opens space to study that communication is not limited to fellow human beings, it is therefore also necessary to understand that communication also occurs with other than humans. THEORY ALAMIN is a branch of science in ALAMTOLOGI which examines communication. Before explaining the definition and development in THEORY ALAMIN, first need to explain the basics of the study that led to the formation of the THEORY ALAMIN . THEORY ALAMIN is formed from the development of the discipline of ALAMTOLOGI. As has been understood ALAMTOLOGI is a science that studies the laws of nature scientifically and systematically based on the process of travel by making nature as a reference. Thus, ALAMTOLOGI can be defined as knowledge applied by using nature as a reference. The definition of nature is meant by HA. ZAMRE in the book ALAMTOLOGY Module is a natural process that moves systematically following its own laws and rules to ensure it is in perfect shape. While science is a result of the process of travel based on experience and implementation. ALAMTOLOGI has the main formula in the process of forming its science of "Formula Principles of ALAMTOLOGI". The form of this formula is formulated as follows:

\section{$X=m / t$}

\section{Figure 1: The formula of ALAMTOLOGI Principles}


The explanation of the formula based on the science of ALAMTOLOGI is a goal to achieve balance, in order to straighten the difference at the point of equation in completing a process. Formulas can be used for balance in forming a theory. The result theory can be applied properly and correctly. The explanation of this formula emphasizes the eternal or fixed value and the value may change. The value " $x$ " is an eternal or fixed value, this value should not be changed. The value of "x" becomes the eternal point of existence at the beginning, " $\mathrm{x}$ " being the starting point of life. The value "m" represents the value of the period that may be changed, as well as the value " $\mathrm{t}$ " represents the value of energy that may be changed. Based on the formula " $\mathrm{x}$ " is the factor that becomes the subject or the originated source of the dubbed. As for the process of finding the value of " $\mathrm{m}$ " there is a solution that can be changed in the approximate basis, it is necessary to use the function of addition of time, reduction of time, division of time and multiplication of the period. The search process of the " $t$ " value also has a solution that can be changed in the approximate basis, so this value needs to be used in the function of distance, breadth, content and speed. A part from the formula $\mathrm{x}=\mathrm{m} / \mathrm{t}$, in the ALAMTOLOGI discipline also described the relation of man to nature and the relationship to the creator in the formula $\mathrm{XYZ}$. In the concept of ALAMTOLOGI, humans are referred to as the $\mathrm{X}$ factor, nature as the factor Z, and the creator of nature as the factor $\mathrm{Y}$. Thus $\mathrm{X}$ is in the position as the task executive, whereas $\mathrm{Z}$ is the reference or reference for $\mathrm{X}$ in performing the task, and $\mathrm{Y}$ is in the position of the giver task to $\mathrm{X}$ which is the creator of $\mathrm{X}$ and $\mathrm{Z}$. Formula $\mathrm{XYZ}$ is very important in the explanation of communication to form THE THEORY ALAMIN. This is because the formula XYZ is a formula that connects people to nature and connects humans with creators.

\section{REVIEW OF LITERATURE}

THEORY ALAMIN was invented by Dr. P.alt. Muhammad Aminullah, MA on July 17, 2016, while reviewing a dissertation study entitled "Human Interaction With Water with Al-Quran approach, ALAMTOLOGI and Communications" at the Doctorate level at North Sumatra State Islamic University of Medan. The study of THEORY ALAMIN has been carried out on July 17, 2013 when the first researchers met directly with the coach and also the founder of the discipline ALAMTOLOGI P.alt 
Masa Bayu. Early learning is to recognize the concept of nature and to know the laws of nature as described in the concept of ALAMTOLOGI The next process of learning to understand the formula ALAMTOLOGI namely $\mathrm{x}=\mathrm{m} / \mathrm{t}$ and the application process of the formula. In this introduction it is apparent that interactions in communication studies can be studied using the formula $\mathrm{x}=\mathrm{m} / \mathrm{t}$. This is because communication can occur not apart from the role of time (time) and energy owned by communicators and communicants. In addition, communication has a main matlamat that is whatever is done in the role is back to the creator. So in the concept of connecting humans with creators in the concept of communication it can be used XYZ formula described in ALAMTOLOGI Based on the results of this study it is the primary responsibility to find a space for communication studies broadly and have the ultimate goal of all its roles. This is due to the concept of communication science that developed during this only relates to human relationships with humankind alone, because the reciprocal intended in communication is reciprocal in the form of verbal and non-verbal that happens among humans, not reciprocal in the form of benefits in the process life. Actually this communication occurs based on the interaction that comes from the relationship between one element with other elements on the basis of the need. Based on the need, it is for humans to achieve the necessities of life necessary to the other elements that exist around him. Such as need to eat, need to drink, need shelter and more. But what distinguishes the interaction between fellow human beings and non-humans is in the form of different interaction execution processes, such as human relationships with animals, plants and also elements of water, soil, fire and wind material. Based on this concept it is necessary to create a special field of study in the science of science that explains the science of communication, the purpose there are two namely to open space in the study of communication science in order to explain scientifically and systematically for the purposes of human relationships with non-human element in this nature , and to find the ultimate matlamah of all interaction processes with the aim of connecting humans with their creators.

THEORY of ALAMIN is the science of ALAMTOLOGI communication. This theory is a discipline of communication science that has different laws and formulas with the existing communication scholarship available. THEORY of ALAMIN has complete scholarship with its philosophy, its law and syllabus which can be practiced in academic world and also the execution time. 
THEORY ALAMIN comes from two basic words of ALAMTOLOGI and AMINULLAH. The combination of these two words is the first study of the concept of communication in the discipline of ALAMTOLOGI, reviewed by AMINULLAH as the name of the reviewer himself. THEORY of ALAMIN is a process of interaction conducted by $\mathrm{X}$ by using $\mathrm{Z}$ space in harmony to achieve the optimum relationship to Y. Based on the definition is very precise THEORY of ALAMIN used as a name for SCIENCE OF ALAMIN COMMUNICATIONS. The science of ALAMTOLOGY communication described in THEORY of ALAMIN gives harmony a communication value to all elements in nature, whether on the smallest element to the greatest element. The process of execution of communication in this THEORY of ALAMIN positioned all the elements of nature right in place and using all the elements of nature based on their needs. This concept can keep all the elements that exist in nature so that no one becomes useless, because the creator also makes everything in nature there is not a single creation that is in vain. The THEORY of ALAMIN formed based on the phenomenon of the development of science of communication that developed so far has not been able to explain and apply forms of interaction that can be done to all non-human elements in harmony. The proof of the use of natural elements so far in the form of objects alone that do not pay attention to the value of mutual benefits between human relationships with non human. Thus, today's world is very clear in need of purification in the science and application in the communication aspect. In fact, the issues and issues that are prevailing around the world must be turned to the lameness of life's implementation. Then the implementation of life is passed on to $\mathrm{X}$ that is human. It is human beings need to understand that where communication problems become the mainstay of defeat (reprisal) and destruction around the world. If $\mathrm{X}$ can use the $\mathrm{Z}$ medium optimally in communicating, it produces the optimum communication value on the connection of connection to $\mathrm{Y}$. However if $\mathrm{X}$ cannot use $\mathrm{Z}$ medium well in communication, then there will be no communication value to $\mathrm{Y}$, turned to $\mathrm{X}$ in the form of countermeasures and damage faced by $\mathrm{X}$ itself. Here it is important to assess and open the scientific space in the field of communication, because it becomes the determinant of human survival in all fields. 


\section{THEORY OF ALAMIN FORMULA}

The Theory Alamin formula that can be considered in the following picture:

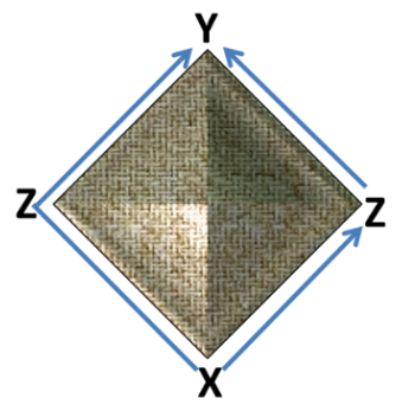

RUMUS:

$\mathrm{X}+\mathrm{Z}(\mathrm{Y})$

$X-Z(0)$

APLIKASI:

1. X Akur rujukan pada Z Mencapai Y

2. X Ingkar rujukan pada Z Tidak mencapai Y

Figure 2: Theory of Alamin Formula

This formula will also be described in this book in the XYZ interaction chapter in ALAMTOLOGI. It should be understood that the interaction of XYZ is the initial process for the establishment of THEORY ALAMIN. This theory is the core point is in the direct relationship X with $\mathrm{Y}$. While $\mathrm{Z}$ is the medium in connecting $\mathrm{X}$ to $\mathrm{Y}$. Therefore it can be understood that the relationship $\mathrm{X}$ with $\mathrm{Y}$ in the environment $\mathrm{Z}$. As for the explanation of THEORY formula can be understood there are two application form that is $\mathrm{X}+\mathrm{Z}(\mathrm{Y})$ and $\mathrm{X}-\mathrm{Z}(0)$. Application form $\mathrm{X}+\mathrm{Z}(\mathrm{Y})$ is $\mathrm{X}$ receive to make $\mathrm{Z}$ as a reference in interaction relationship, then $\mathrm{X}$ can connect communication with $\mathrm{Y}$. While $\mathrm{X}-\mathrm{Z}(0)$ $\mathrm{X}$ application form refuse to make $\mathrm{Z}$ as reference in interaction relationship, then $\mathrm{X}$ cannot communicate communication with $\mathrm{Y}$, therefore $\mathrm{X}$ is in empty state that does not have the purpose of being the value achieved than the purpose of communication. The use of $\mathrm{Z}$ as a medium in connecting $\mathrm{X}$ with $\mathrm{Y}$ in THEORY of ALAMIN has four fixed laws of $\mathrm{Z}$ as position, $\mathrm{Z}$ as the introduction process, $\mathrm{Z}$ as isyarah (signal), and $\mathrm{Z}$ as survival (source of life). Thus, $\mathrm{XYZ}$ interaction can occur when $\mathrm{X}$ stick to media $\mathrm{Z}$ to be able to connect with Y. The interaction law in THEORY of ALAMIN is four that is the interaction used in $\mathrm{X}$, the interaction is valid only in $\mathrm{Z}$ environment, the interaction process has $\mathrm{Z}$ as the reference, and the interaction can brings added value to $\mathrm{X}$. The application of THEORY of ALAMIN is formula based on the image above there are two namely $\mathrm{X}$ the reference at $\mathrm{Z}$ reaches $\mathrm{Y}$ and $\mathrm{X}$ reference on $\mathrm{Z}$ does not reach $\mathrm{Y}$. Explanation $\mathrm{X}$ referring to the reference $\mathrm{Z}$ on $\mathrm{Y}$ that $\mathrm{X}$ is doing 
communication in the form of $\mathrm{X}$ relationship with $\mathrm{Z}$ by way of $\mathrm{X}$ follow $\mathrm{Z}$ law appropriately in the use of element $\mathrm{Z}$ according to the needs of $\mathrm{X}$, not of the desire of $\mathrm{X}$. The accuracy of following Z's law is called agreed. Accurate in the communication concept of THEORY of LAMIN ie X follows the rules available in referring to $\mathrm{Z}$. Therefore in the process of communication execution, $\mathrm{X}$ follow the four laws that are reasonable, think, effort and effort. Based on this concept, any interaction made by $\mathrm{X}$ to achieve the objective to $\mathrm{Y}$, must follow the four laws that are compatible. For example $\mathrm{X}$ requires to eliminate thirst, then $\mathrm{X}$ needs to use the mind to think of finding the right thing to be able to eliminate thirst, in this concept $\mathrm{X}$ need to find water. Further $\mathrm{X}$ needs to use the effort that is the right tool inventory so that water can be used in accordance with its purpose, for example glass. And finally is the effort that $\mathrm{X}$ needs to do the process of drinking water in a proper way. Therefore, the implementation of drinking water by using the law agreed, then the process becomes a favorable value obtained by $\mathrm{X}$ in the implementation of interaction, so that it can understand the value is on the granting of the $\mathrm{Y}$ as the water creator that can function to eliminate thirst. The explanation of $\mathrm{X}$ references on $\mathrm{Z}$ does not reach $\mathrm{Y}$ ie $\mathrm{X}$ interact with the way of denying the law of $\mathrm{Z}$. Therefore if $\mathrm{X}$ loop $\mathrm{Z}$, then $\mathrm{X}$ does not have a clear point. There are four laws of forgetfulness, wanting, greedy, and wasteful. The non-goal achievement of $\mathrm{Y}$ from the interaction process $\mathrm{X}$ to $\mathrm{Y}$ is called (0). (0) in THEORY ALAMIN that has no objective of the interaction application that is booked by $\mathrm{X}$, because it denies the existing reference law on $\mathrm{Z}$ as a medium in the process of interaction $\mathrm{X}$ with $\mathrm{Y}$. The main cause of failure or obstacle in communication caused by inappropriate media used by communicators. So in this concept if $\mathrm{X}$ is not exactly using $\mathrm{Z}$, surely not reaching communication in relationship $\mathrm{X}$ to $\mathrm{Y}$.

\section{BASIS PHILOSOPHY ALAMIN THEORY}

It should be understood that every study of science, there must be a foundation of philosophy from the study of science discussed. Philosophy is the basic grip to become a force in the application of such science. Therefore in philosophy need to understand about the nature of science, how to understand and get science and the benefits or usefulness that makes a value in the science. The philosophy in the discipline of ALAMTOLOGI not only limited to the nature, knowledge and value 
alone, but more emphasis on the nature of the science. Thus the meaning of philosophy based on the discipline of ALAMTOLOGI is the nature of something to something. For example water, then the philosophy of water is flowing. Why flow? Because water has four laws, ie has no fixed form, follows another form, gentle and firm. Based on the basic understanding of the philosophy, it should be understood that THEORY ALAMIN also has its philosophy. The philosophy of THEORY ALAMIN is "everything that exists in $\mathrm{Z}$ environment, must have a communication relationship with $\mathrm{X}$ ". Explanation of communication in THEORY ALAMIN is communication occurs on the relationship with each other based on the need. For example, the relationship of man to the land is found in the human need to the ground for a foothold for man. so does the human relationship with water to have fluid in the human body and also the connection with wind, fire and others in all the elements present in nature. Based on the philosophy of THEORY ALAMIN as already mentioned, then this concept can be proved that the element $\mathrm{X}$ must exist in $\mathrm{Z}$ and also element $\mathrm{Z}$ must exist in $\mathrm{X}$. For example: the water that is in the earth is also gained in man such as blood, urine, tears and also saliva. So also all kinds of animal sounds that exist in nature, humans must be able to imitate the sound. This concept in THEORY of ALAMIN can be understood that $\mathrm{X}$ is a joining element of the element $\mathrm{Z}$, while $\mathrm{Z}$ is the element from the element $X$. It means that all elements in nature must exist in humans and all the elements that exist in humans must exist in nature. So in THEORY of ALAMIN, $\mathrm{X}$ is a macro $\mathrm{Z}$, and $\mathrm{Z}$ is a micro $\mathrm{X}$. $\mathrm{X}$ can be mentioned as a merger of all elements of $\mathrm{Z}$ because the merging process can be understood from the process of human creation as described in the ALAMTOLOGI discipline. The orderly process rules are water, steam, gas, materials, plants, animals and humans. this concept states that man is the ultimate element of creation, because in man has all the content of the six elements mentioned. The explanation of the connection in the process of human creation is the basis of human relationships with all the elements that exist in nature. But in the structure of the human body also has elements of macro and micro elements. The macro element in humans is the whole human body that has been composed completely, while the micro elements in the human body that is fragments of each organ in the human body such as hands, feet, fingers, ears, nose, mouth, stomach, intestine, liver, brain, head and so on. But from each of these micro elements have communication among the elements, because each element has a relationship that cannot be separated with the other. As it is necessary to drink water, it requires a 
hand to be able to take water, then need a mouth to drink water and so on the next process so that water can be drunk well to meet the purpose rather than drinking the water. The communication process in the formation of the relationship $\mathrm{X}$ with $\mathrm{Z}$ as a medium for $\mathrm{X}$, then $\mathrm{X}$ requires the factor and the power factor that existed in $\mathrm{Z}$ to achieve the communication process. This is because the role of $\mathrm{X}$ cannot be separated from the time factor and also the power factor. Period and power is one of the main elements that exist in $\mathrm{Z}$, then $\mathrm{X}$ is conquered in these two factors. This proves that if there is no $\mathrm{Z}$, then $\mathrm{X}$ cannot exist. In addition to that in the communication process based on THEORY of ALAMIN, $X$ has two roles in the execution of communication to be able to connect the role of $\mathrm{X}$ with $\mathrm{Z}$, namely the role on the use of the sense factor and liver factor.

The intellect factor in THEORY of ALAMIN is to manage the communication process appropriately on the basis of necessity. While the heart factor in THEORY of ALAMIN serves to make decisions every case in the communication process that has been prepared by the intellect. Then the heart requires reason to tell all the implementation process before making a decision. Thus if the heart does not use reason, then the decision certainly does not have the right rules. Thus it can be understood that the communication process can be disrupted if the decision of the heart is not through the rules of reason. Failure and error in communication based on THEORY of ALAMIN other than the unbalanced factor and energy factor, is also influenced by the role of the heart in making decisions beyond the role of reason. The foundation of the philosophy of THEORY of ALAMIN based on the approach of ontology, epistemology and axiology can be understood as follows.

\section{Ontology}

Ontology in the study of philosophy is the essence of something. To know something needs to know the nature of something. As to know the stone, then the essence of stone is a form of stone and stone properties. This explains that everything has the essence to be known, as well as THEORY of ALAMIN has a basic essence to know the theory. The basis of ontology on THEORY ALAMIN is PURPOSE. The Nature of THEORY of ALAMIN is the necessity of something to something. Based on these requirements form an interaction that can connect with each other. This process of relationship is called the origin of communication. The nature of the implementation of communication in THEORY of ALAMIN is a process of communication in the creature, because the creature is the 
created element. It is therefore understandable that communication in THEORY of ALAMIN is the communication between $\mathrm{X}$ and $\mathrm{Z}$ to attain to $\mathrm{Y}$. Based on the concept of THEORY of ALAMIN, then every creature must have a relationship with other among fellow beings to reach the relationship to its creator. This is because the essence of the creature cannot stand by itself without relation to other elements. Thus, human nature can communicate with all elements of nature on the basis of human need to all elements of nature as a medium for the achievement of life necessities in providing evidence of responsibility to the creator. As in the concept of ontology, THEORY of ALAMIN has three stages of communication form, communication process and the nature of communication, as can be seen in the following figure.
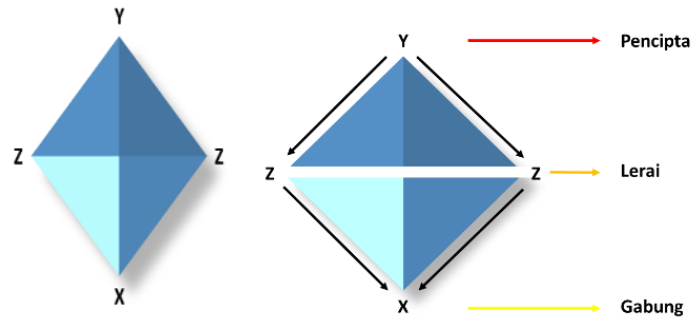

Figure 4

Figure 3

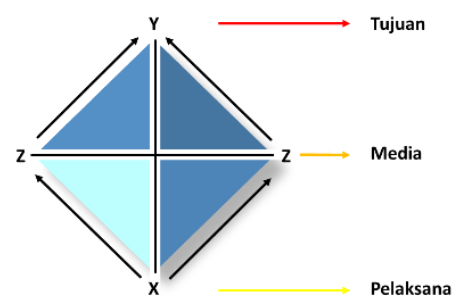

Figure 5

Communication Process

The Nature of Communication

\section{Epistemology}

Epistemology in the study of philosophy of science that is explaining about how to get knowledge of something or called as a method to gain knowledge of a science. In the process of epistemology everything also needs to be understood how a knowledge can be obtained, why the need for a knowledge. The basis of epistemology in THEORY ALAMIN is how to know the existence of $X$ communication with $\mathrm{Z}$ to reach to $\mathrm{Y}$, why $\mathrm{XYZ}$ communication needs, and how the communication process is done by $\mathrm{X}$ by using media $\mathrm{Z}$ to reach to $\mathrm{Y}$. The way to know the existence of $\mathrm{X}$ communication with $\mathrm{Z}$ as a medium to reach to $\mathrm{Y}$ in THEORY ALAMIN can be understood based on existing processes in natural law. Natural laws based on the discipline of ALAMTOLOGI there are four forms, levels, pairs and balance. The explanation can be understood as follows: 
a. The form of communication based on THEORY ALAMIN is the form of interaction arrangement as mentioned in Figure A.2. this form explains that the communication made by $\mathrm{X}$ through the process of using existing media on $\mathrm{Z}$ to connect to $\mathrm{Y}$. Meaning $\mathrm{X}$ to communicate in life to achieve to the highest rank that is $\mathrm{Y}$, then $\mathrm{Y}$ is on top of all elements $\mathrm{Z}$ and $\mathrm{X}$

b. Level in the process of implementation of communication based on THEORY ALAMIN is every communication made by $\mathrm{X}$ to reach to $\mathrm{Y}$ remain in space $\mathrm{Z}$. Therefore it can be understood that $\mathrm{X}$ is not separated and out of space exist in $\mathrm{Z}$. Space $\mathrm{Z}$ is the limit of levels that can be taken by $\mathrm{X}$ in conducting the communication process, including space and labor space.

c. Couples in the communication process based on THEORY ALAMIN every communication process has a partner on the perpetrators of communication and messages. The pair on the communications actors are $\mathrm{X}$ as a communicator and $\mathrm{Z}$ as a communicant. Then the reciprocal message becomes the form of the message pairs in the communication process. Each implementation of $\mathrm{X}$ in performing the assignment given by $\mathrm{Y}$ is a form of message delivery, whereas the result that is found rather than the implementation process is the message in the form of a response back to implementers. As $\mathrm{X}$ keeps the water clean, the willingness of the water is always clean in response to its implementation.

d. Balance on communication based on THEORY ALAMIN $\mathrm{X}$ carry out the process of communication in the form of properties that are compatible to $\mathrm{Z}$. Thus every communication process conducted by $\mathrm{X}$ always uses four legal processes in an orderly manner that is sense, thought, endeavor and end with effort. Based on the discussion, then how to know the existence of $\mathrm{XYZ}$ communication based on the law of nature that there are elements of $\mathrm{Z}$ in good condition and does not cause damage to the element $Z$.

This is the result of the implementation of communication made by $\mathrm{X}$ in the form of accurate and targeted communication process. The way to know the existence of communication in THEORY of ALAMIN based on the law of $X$ that is every process of communication execution conducted by $X$ based on four fixed law owned by $\mathrm{X}$. The four laws $\mathrm{X}$ are science, culture, creativity and economy. Based on this concept can be understood that every implementation of communication made by $\mathrm{X}$ is the science of $X$, while the truth of the implementation of the science of $X$ is a form of culture in self 
$\mathrm{X}$. Creativity is found on the wider development of the science possessed by X. Likewise on the economic rank is found rather than the creative earnings of science developed into benefits to all elements of Z. Further studies in epistemology based on THEORY of ALAMIN about why the need for $\mathrm{XYZ}$ communication is so that $\mathrm{X}$ can recognize the position and role of each. The position and role of $\mathrm{X}$ in THEORY of ALAMIN can be seen in figure A.4, $\mathrm{X}$ as the executor in the communication process to reach to $\mathrm{Y}$. Based on the position of $\mathrm{X}$ as the executor, $\mathrm{X}$ is responsible for all execution done during life process. With the communication that can connect XYZ, then $\mathrm{X}$ can communicate appropriately in using $\mathrm{Z}$ as a medium to achieve goals rather than communication. Based on the discussion it can be understood that $\mathrm{X}$ needs media $\mathrm{Z}$ to be achieved communications to $\mathrm{Y}$ as proof of responsibility for the implementation of the assignment set by $\mathrm{Y}$ to $\mathrm{X}$. The epistemological foundation in THEORY ALAMIN about how the communication process is done by $\mathrm{X}$ by using media $\mathrm{Z}$ to reach to $\mathrm{Y}$ that $\mathrm{X}$ can communicate based on seven ranks in an orderly manner that must be owned by $\mathrm{X}$ itself in running the task. The seven ranks are acceptance, execution, patience, refinement, thoroughness, tranquility, and sincerity. These seven rankings will be described in this book on the discussion of human application processes in life. The process of using $\mathrm{Z}$ media in THEORY of ALAMIN can be done in several ways ie the use of everything that is in element $\mathrm{Z}$ based on the required level, $X$ need to always keep the existing potential on element $Z$ well, $X$ need to maintain the element $\mathrm{Z}$ in order to avoid damage, and $\mathrm{X}$ need to nurture every potential available in the $\mathrm{Z}$ element to make a source of benefit to others. Based on the discussion of epistemological foundation in THEORY of ALAMIN, it can be understood that $X$ understands and knows how to use media $Z$ in the communication process to reach the relationship to $\mathrm{Y}$ as the assignor to $\mathrm{X}$. Thus, $\mathrm{X}$ recognizes and understands the level of $\mathrm{X}$ as a potential for $\mathrm{X}$ in making the right decisions in the implementation of the task. $\mathrm{X}$ also recognizes the limits of the existing content in $\mathrm{Z}$ as the limit of potential communication that can be done by $\mathrm{X}$. X can know in the communication process that cannot be out of the level possessed by $\mathrm{Z}$ to reach the relationship to $\mathrm{Y}$.

\section{Axiology}

Axiology is a process of outcomes or the value of benefits derived from a science that is awakened. This is indispensable in the foundation of the philosophy of science, so that every science 
developed can be understood not to occur value-free in the application process. Such as the creation of a knife to cut, but when the knife is used to kill, then the definition of the blade remains as a cutting tool. The use of a knife to kill still should not be a shift in the value of the essence of the knife definition. Then the process of killing with a knife is a process of mistake the use of a knife, not the purpose rather than the creation of the knife. The axiological foundation in THEORY of ALAMIN is to establish harmony in communication made by $\mathrm{X}$ by using media $\mathrm{Z}$ to achieve the right relationship to Y. Axiological value is emphasized in THEORY of ALAMIN that is to achieve the value of harmony in the process of communicating. Benefits found in communication based on THEORY of ALAMIN is that all elements of media that exist in $\mathrm{Z}$ can be maintained properly in its use. While the main purpose of communication in THEORY of ALAMIN is to achieve a proper relationship rather than $\mathrm{X}$ to $\mathrm{Y}$ on the implementation and the responsibilities given in space $\mathrm{Z}$. In this concept it can be concluded that how $\mathrm{X}$ uses media $\mathrm{Z}$ in communicating, then that is the result of communication connected to $\mathrm{Y}$. The good use of media can produce good communication. Unfavorable use of media can result in poor communication. This is the essence of axiology in THEORY of ALAMIN about the value of XYZ communication.

\section{ACHIEVEMENT OF ALAMIN THEORY}

Achievement is the target or the main target in each study. The one targeted in THEORY of ALAMIN is "to produce the optimum relationship between $\mathrm{X}$ and $\mathrm{Y}$ ". This concept is very important in this study as the basic concept can be seen in Figure A.2. Communication process based on THEORY ALAMIN ie $\mathrm{X}$ accepts assignments from $\mathrm{Y}$ through $\mathrm{Z}$, then $\mathrm{X}$ performs its task in space $\mathrm{Z}$, then $\mathrm{Z}$ becomes the medium that connects $\mathrm{X}$ to $\mathrm{Y}$ as proof of the result of the implementation done by $\mathrm{X}$. Based on the communication process described, the basic achievement in the achievement of XYZ communication based on THEORY of ALAMIN, which is to produce the X relationship with the optimum Y. The attainment of NATURAL THEORY is very important to make a proper communication concept, because everything must require one main goal. This is what is mentioned in the formula formula of THEORY ALAMIN $\mathrm{X}+\mathrm{Z}(\mathrm{Y})$. (Y) is the achievement of $\mathrm{X}+\mathrm{Z}$. $\mathrm{Z}$ is very 
important in the communication process because $\mathrm{Z}$ has a position as a medium that produces an executing relationship $\mathrm{X}$ to $\mathrm{Y}$. Then $\mathrm{X}$ must use and refer $\mathrm{Z}$ in the form of "+" as the process of acceptance of role $\mathrm{Z}$ as media which is appropriate in generating a relationship to $\mathrm{Y}$. However, if $\mathrm{X}$ refuses in the form of "-" to receive $\mathrm{Z}$ as the medium, then the communication process carried out by $\mathrm{X}$ does not have the matlamat it accrues. Failed or not achieving communication $\mathrm{X}$ to $\mathrm{Y}$ based on the concept of THEORY of ALAMIN called (0). (0) is the value of failure or failure to achieve communication objectives in THEORY of ALAMIN. The objectives in THEORY of ALAMIN have four objectives to achieve, namely the form of connecting $\mathrm{X}$ to $\mathrm{Y}$, the way to connect $\mathrm{X}$ to $\mathrm{Y}$, the destination connected $\mathrm{X}$ to $\mathrm{Y}$, and the results specified as achievements in THEORY of ALAMIN. The $\mathrm{X}$-linked form to $\mathrm{Y}$ is by way of $\mathrm{X}$ using a maintained reference and not damaging media $\mathrm{Z}$ as proof of implementation of $\mathrm{X}$ over running the mandate set by $\mathrm{Y}$ optimally. Then formulation of the form of communication that is $\mathrm{X}+\mathrm{Z}(\mathrm{Y})$. How to connect $\mathrm{X}$ to $\mathrm{Y}$ that $\mathrm{X}$ performs the assigned tasks of $\mathrm{Y}$ in space $\mathrm{Z}$ by maintaining and keeping from the damage of $\mathrm{Z}$ in the optimum stage, as assigned by $\mathrm{Y}$ "do not make any damage to the earth" means that $\mathrm{Z}$ space needs to be maintained with optimum. The purpose of connecting $\mathrm{X}$ to $\mathrm{Y}$ is the proof of responsibility for the implementation of $\mathrm{X}$ as assigned by $\mathrm{Y}$. The purpose of each exercise is very important, because an implementation that has no purpose is useless. Then this is the most basic message taught to $\mathrm{X}$ that every element created on $\mathrm{Z}$ is nothing to nothing. While the results are specifically obtained that form the results XYZ relationship optimum in the form of a harmony relationship.

\section{IMPLEMENTATION OF ALAMIN THEORY}

Implementation of THEORY of ALAMIN is a form of communication benefits that can be applied directly by $\mathrm{X}$ in the process of implementation of the task. Implementation of THEORY ALAMIN is very important to explain to be the value of contribution to others. The main characteristic in the implementation of THEORY ALAMIN there are four rational nature that is scientific, systematic, empirical and universal. Implementation scientifically that communication in THEORY ALAMIN can be formulated based on the communication done in the form of $\mathrm{X}+\mathrm{Z}(\mathrm{Y})$ and $\mathrm{X}-\mathrm{Z}(0)$. 
While the explanation is based systematically that $\mathrm{XYZ}$ communication in THEORY is $\mathrm{X}$ make optimum communication in using $\mathrm{Z}$ media with optimum, then $\mathrm{X}$ can produce the optimum relationship with $\mathrm{Y}$, called generic harmonic pattern ( $\mathrm{g} \mathrm{Hp}$ ). If $\mathrm{X}$ does a communication that does not reach the optimum value in using $\mathrm{Z}$ media, then $\mathrm{X}$ cannot achieve the optimum relationship with $\mathrm{Y}$, called generic corrupted pattern ( $\mathrm{g} \mathrm{Cp}$ ). The optimum form of communication is communication that does not cause damage and destruction of existing media elements in $\mathrm{Z}$. As it does not damage the clean water cycle to achieve clean water, the goal is to get health value for anyone consume clean water. The implementation of THEORY ALAMIN empirically is the implementation of keeping the elements of media $\mathrm{Z}$ well in the optimum ranking can be done significantly. While the implementation in the universal form of this process of THEORY ALAMIN can be done by anyone in the form of real and practical. Like keeping water clean when drunk, the process of keeping the water clean for drinking can be done by anyone using a clean glass and putting the water in a clean place as well. As for any theoretical formation, it should briefly satisfy the four elements of the function of the theory of defining functions, explaining functions, predicting functions and predicting functions. Based on the explanation of four standard functions of theory, the THEORY ALAMIN has four functions:

\section{a. Function defining}

THEORY ALAMIN can be defined that is a process of interaction in the communication made by $\mathrm{X}$ by using space $\mathrm{Z}$ in harmony to achieve the optimum relationship to $\mathrm{Y}$. Based on the definition of THEORY ALAMIN, then the communication formula in THEORY ALAMIN is based on the following figure :

\section{$\mathrm{X}+\mathrm{Z}(\mathrm{Y}) \rightarrow \mathrm{gHp}$ $X-Z(0) \rightarrow g C p$}

Figure 6: The formula of communication in THEORY ALAMIN

Based on the formula of THEORY ALAMIN, then XYZ communication can be understood there are two forms namely; First, if $\mathrm{X}$ communicates by using $\mathrm{Z}$ media in harmony, then $\mathrm{X}$ can reach the 
optimum relationship to $\mathrm{Y}$. Secondly, if $\mathrm{X}$ communicates by using $\mathrm{Z}$ media inharmoniously (can damage $\mathrm{Z}$ media), then $\mathrm{X}$ does not achieve result 0 ).

\section{b. Function explaining}

NATURAL THEORY can explain an insight that can be developed rather than the development of that theory. The insights that can be developed in THEORY ALAMIN is that this theory can be applied scientifically and systematically in everyday life. This is because THEORY ALAMIN describes communication formed from an interaction that can connect to each other on a need basis. Based on this explanation can be understood that every need to something must be done an interaction to get something that is needed. The form of application in the process of implementation of this interaction also requires the media to get something that is needed. But what distinguishes each interaction process is found in different methods and media. Methods and media follow the required elements. As $X$ requires water to drink, then the medium used to get water is glass. Likewise if $X$ requires rice to eat, then the medium used to get the rice is a plate. The explanatory functions contained in THEORY ALAMIN that can be applied by using the existing media in the element $\mathrm{Z}$ based on the right needs with the purpose of communication. Thus it can be understood that all elements of $Z$ can be interacted with $\mathrm{X}$ by means of the use of elements $\mathrm{Z}$ must be precise with the needs rather than $\mathrm{X}$. If inappropriate use of existing media on element $\mathrm{Z}$, then communication made by $\mathrm{X}$ becomes obstacles and challenges in communication achievement for can produce an optimum relationship, both fellow $\mathrm{X}$, also to $\mathrm{Z}$ and especially to $\mathrm{Y}$, as the ultimate achievement of all life's implementation processes.

\section{c. Function prediction}

THEORY ALAMIN based on forecasting functions can be used for theory development planning in universal interaction execution. THEORY ALAMIN can develop a form of interaction implementation not limited to one object only. But the execution can be developed to all the elements that exist in this realm, the meaning of this theory can be applied in the space of $\mathrm{Z}$. Based on the concept, the THEORY ALAMIN can form various other theories related to communication in the scope related to XYZ. As can develop the theory of human communication with the element of water, the theory of human communication with the elements of the land, the theory of human communication with the elements of the wind, the theory of human communication with the element of fire, the theory 
of human communication with plants, the theory of human communication with animals, that exist within the element. Likewise, this NATURAL THEORY also opens space for studying and shaping communication theory in macro and micro forms. The concept of developing a variety of other theories, in fact back to the most basic concept, as described in NAMELY THEORY is the interaction occurs on the need. Then the interaction that produces this relationship makes the value to the formation of a communication.

\section{d. Prediction}

THEORY of ALAMIN can have predictive value, but THEORY ALAMIN is producing a certainty of the value of the results achieved rather than the result of the execution of the task. Certainty of value in its use, that communication in this theory can be done by anyone,not differentiate race, race, nation and state. This is because communication is formed by the interaction based on the need. Whatever is required must be through the interaction made to connect with his needs. Thus, the communication based on THEORY ALAMIN can achieve the certainty of the results of its use is universal. THEORY ALAMIN can be used to recognize the position of self $X$ as the executor of the life process in space $Z$. Therefore $X$ can recognize the responsibility of self $X$, then $X$ must be the keeper, guard, bodyguard and builder in space $\mathrm{Z}$ at the optimum rank. Besides that, the THEORY ALAMIN can also be used to recognize the position of $Z$ and recognize the implementation of the trust to $\mathrm{Z}$, then $\mathrm{X}$ is not a destruction and harmony of harmony in space $\mathrm{Z}$. Based on this concept, the use of THEORY ALAMIN can be a commitment to achieve the equilibrium value based on $x=m / t$ in forming a harmony relationship $\mathrm{X}$ with $\mathrm{Z}$, the goal is to generate an optimum relationship to $\mathrm{Y}$. Because $\mathrm{Y}$ is the assignor to $\mathrm{X}$ based on the outcome of his creation.

\section{CONCLUSION}

As for the conclusions that are accomplished rather than the implementation of THEORY ALAMIN there are four main ranks: science, culture, creativity and economy

a. Implementation of THEORY ALAMIN on the achievement of science that is this theory becomes the basic formula for the science of communication to open space wider communication studies to 
all elements $\mathrm{Z}$. This means that the scope of the study of communication is no longer limited among fellow human beings, but with the existence of THEORY ALAMIN can understand the application of interaction with non-human in a scientific and systematic form to produce harmony values.

b. Implementation of THEORY ALAMIN on the achievement of a culture that is the implementation of this theory can form the value of consciousness $\mathrm{X}$ as the executor of the task of $\mathrm{Y}$ to maintain the prosperity Z. Thus THEORY ALAMIN can explain the actual form of human consciousness in appreciating all the elements in nature to be a reference to humans for facing its Creator. The truth and value wisdom generated in the communication process by $\mathrm{X}$ becomes the optimum result in forming a relationship to $\mathrm{Y}$.

c. Implementation of THEORY ALAMIN on the achievement of creativity is to build awareness of communication to be able to form space $\mathrm{Z}$ into projects "environmentally friendly". THEORY ALAMIN aims to use and utilize elements of $Z$ to foster a program that produces gloriousness for $\mathrm{X}$, but does not destroy elements Z. As X can build natural tourist sites in forest areas, X must maintain the beauty is always guaranteed and maintained from the damage. This method needs to regulate wise development and not damage existing resources. As for the creation of creativity value there are four steps that must be done before carrying out its duty is to use the mind, think optimum value of benefits, endeavor in preparing the right job equipment, and try with optimum to achieve optimum results.

d. The implementation of THEORY ALAMIN on economic achievement is that this theory explains the use and utilization of $\mathrm{Z}$ elements based on the result of environmentally friendly interaction, to produce prosperity value for self $\mathrm{X}$ and others. The value of prosperity rather than the optimum results of communication in $\mathrm{XYZ}$ relationships becomes an appropriate economic source for $\mathrm{X}$ and others. As X builds eco-friendly natural tourist sites, then all the elements of life in the area must be well preserved so as not to damage all the ecosystems in the vicinity. Thus, $\mathrm{X}$ can achieve economic results from his efforts, but no $\mathrm{Z}$ elements are damaged. With this $\mathrm{X}$ has run the mandate assigned by $\mathrm{Y}$ to "do not make damage on earth". It can be concluded THE NATURAL THEORY can deliver $\mathrm{X}$ in executing the $\mathrm{Y}$ command to prosper $\mathrm{Z}$. 


\section{REFERENCES}

B. Aubrey Fisher, terj: SoejonoTrimo, Teori-TeoriKomunikasi, Bandung: RemajaKarya, 1986

HA Zamre, Modul ALAMTOLOGI: Pengenalan ALAMTOLOGI, jld. 1, Kuala Lumpur: Nature Pattern Resources Sdn. Bhd, 2013

Hardonohadi, Epistemologi: Filsafatpengetahuan, Cet. 11, Yogyakarta: Kanisius, 1994

LaesSudibyo, FilsafatIlmu, Cet. 1, Yogyakarta: Deepublish, 2014

Martha Tilaar, KecantikanPerempuanTimur, cet. 1, Magelang: Indonesia Tena, 1999

Muhammad Aminullah, Alamtologi: InteraksiManusiaDengan Air, Jilid I, Kuala Lumpur: Nature Pattern Resources Sdn. Bhd, Cet. 1, 2017

Muhammad Aminullah, KomunikasiAlamtologi: TeoriAlamin, Jilid I, Kuala Lumpur: Nature Pattern Resources Sdn. Bhd, Cet. 1, 2018 